ORIGINAL ARTICLE

\title{
Snowblading injuries in Eastern Canada
}

\author{
E J Bridges, F Rouah, K M Johnston
}

Br J Sports Med 2003;37:511-515

\begin{abstract}
Objectives: To evaluate injury patterns of snowbladers and compare them with those of skiers and snowboarders. To determine possible effects of helmet use in these sports on injury to the head and neck. Methods: This prospective case series observational study was conducted by collecting the injury reports from the ski patrol during the 1999-2000 season at Mont Tremblant ski resort, Quebec. All participants in downhill winter sports who presented themselves to the ski patrol with traumatic injury related to their sport were included. A concussion was defined as any loss of consciousness, amnesia, confusion, disorientation, vertigo, or headache that resulted from injury. The ski patroller reported helmet use on the accident report at the time of injury.

Results: Snowbladers present with a unique pattern of injury compared with skiers and snowboarders. The incidence of leg, knee, and ankle/foot injuries were $20.5 \%, 25.6 \%$, and $10.3 \%$ respectively. Concussions represented $11 \%$ of all injuries. There was no increase in other injury, including neck injury, related to helmet use.

Conclusions: Unique injury patterns in snowbladers warrant reconsideration of equipment design. Concussion is a common injury on the ski slope. Although the effects of helmet use on concussion rate are inconclusive based on this study, helmet use did not increase the rate of neck injury, even when adjusted for age.
\end{abstract}

See end of article for authors' affiliations

Correspondence to: Dr Bridges, McGill Sports Medicine Center 475 Pine Avenue West, Montreal, Quebec, Canada H2W 1S4; eileenb@ogc.ca

Accepted 21 January 2003

Accepted 21 January 2003

S kiing and snowboarding are popular winter sports in Eastern Canada. Recently there has been a growing trend for "snowblades", short skis with fixed bindings used with a conventional ski boot. Their popularity is due to the short, quick carving turns and aerial manoeuvres that can be carried out, as well as their use in lessons to teach balance in the fore and aft direction during skiing. No studies to date have documented the injury patterns associated with snowblading.

Although several studies have previously defined the risk and injury characteristics of skiing and snowboarding, ${ }^{1-24}$ there have been a number of questions that remain unanswered. For example, there have been few studies documenting the use of helmets and whether other injuries, particularly to the neck, occur as a result of wearing helmets while skiing or snowboarding.

Therefore this study was undertaken to determine whether using a helmet for skiing or snowboarding caused an increased risk of other injury, in particular neck injury and to describe the general injury patterns associated with snowblading.

\section{PATIENTS AND METHODS}

A prospective case series investigation was conducted to determine the injury patterns in skiers, snowboarders, and snowbladers at an Eastern Canadian resort (Mont Tremblant). Ski patrollers are present on the hill at all times that the resort is open from November to April. They are volunteers who have undertaken standard certification by a trauma expert. All injuries reported to the ski patrol during the 1999-2000 winter season (November 1999 to April 2000) were assessed, and the patroller completed a comprehensive report on a standard Quebec accident form. The report documented personal information such as the injured person's age, sex, self reported ability, past participation in lessons, and equipment ownership. The patrollers documented site of injury, their assessment of the type of injury, and the circumstances surrounding the injury including weather conditions, snow conditions, cause of injury, and time of day.
An instructional session on the recognition of head injury and concussion was held before the start of the season by a neurosurgeon with expertise in this field. Concussion symptoms were documented on the report in the comments section and cross referenced to the diagnosis on the report. Concussion was defined as any loss of consciousness, amnesia, confusion, disorientation, vertigo, or headache that resulted from injury while participating in activity at the resort.

Consent for data use for this study was obtained from the resort involved. The reports were stored at the dispatch control at the mountain. Photocopies were collected at the end of each week, and the information entered into a database for analysis. Inclusion criteria for the analysis were a traumatic injury incurred while participating in a sporting activity on the hill and assessment by a ski patroller. Any report forms for medical conditions or those for mountain workers (lift operators, equipment drivers) were not included in the analysis.

The director of the ski school, the patroller in charge, and the general manager of the resort were interviewed and asked to report an approximate proportion of the participants in various activities performed on the hill. The activities were divided into skiing, snowboarding, snowblading, and telemarking.

\section{Statistical methods}

All analyses were performed using the SAS software. ${ }^{25}$ We used analysis of variance to compare the mean age of skiers, snowboarders, snowbladers, and telemarkers, or $t$ tests when only two groups were compared. For contingency tables, $\chi^{2}$ tests were used to determine whether the variables were dependent on the type of activity practiced (ski, snowboard, snowblade, telemark). Because of the low numbers of telemarkers in our sample $(n=6)$, we excluded them from some analyses, and examined differences between skiers, snowboarders, and snowbladers only.

To examine possible risk factors for concussions, a logistic regression model was used, with outcome defined as having a 
concussion versus having some other injury. Adjusted odds ratios and corresponding 95\% confidence intervals (CI) are reported. ${ }^{26}$

\section{RESULTS}

There was 1332 injury reports filed for the 1999-2000 season at Mont Tremblant, with a total of 1494 injuries (162 people had more than one injury). Six of the injuries were in telemarkers, who were excluded form the analysis. Table 1 presents a list of the characteristics of those presenting to the ski patrol with an injury during the 1999-2000 season. Most injuries occurred as a recreational activity (80\%), after between two and five hours of participation that day $(80 \%)$, on a clear day $(60.4 \%)$, on hard packed or machine groomed snow $(57.8 \%)$, with good visibility $(81.0 \%)$ and in natural light $(98.8 \%)$. In the snowboarders who were injured, $21.9 \%$ of injuries occurred in the snow park (half-pipe, table tops, rail, etc), and $17.6 \%$ of injuries involved jumping. For snowbladers, it was the first day on the hill for $38.2 \%$ of injured participants, which was significantly different from skiers and snowboarders $(19.6 \%$ and $16.5 \%$ respectively, $\mathrm{p}=0.001$ ).

Figure 1 gives the breakdown of injuries (including multiple injuries) according to body site. Most (83\%) of the head injuries (147/179) were concussions. Concussions represented $11 \%$ of all injuries. Not all of the information could be reported from concussed patients, as there were various levels of consciousness in the injured participants. Male participants suffered significantly more concussions than female participants $(13.2 \%$ and $8.2 \%$ respectively, $\mathrm{p}=$ $0.0041)$. Most concussions occurred after between two and five hours of activity $(57.7 \%)$ and in intermediate participants $(49.6 \%)$. Most people reporting concussions had never had a lesson $(32.3 \%)$ and were free skiing $(84.1 \%)$. Some $13.1 \%$ of all injuries involving a jump were concussions, and most concussions occurred as the result of participant error (loss of balance, fall, catching an edge) (fig 2). The proportion of injuries resulting in concussions was significantly different among the groups $(\mathrm{p}=0.0056)$, representing $9.6 \%$ of all injuries in skiers, $14.7 \%$ of injuries in snowboarders, and $5.7 \%$ of injuries in snowbladers (fig 3 ). Those people with neck injuries also experienced significantly more concussion symptoms than those without neck injuries $(39.5 \% \vee 10.2 \%$ respectively, $\mathrm{p}<0.0001)$. There were no significant differences in the proportion of helmet use among skiers $(17.4 \%)$, snowboarders $(16.7 \%)$, and snowbladers (11.4\%) ( $\mathrm{p}=0.4612)$. There was no increased incidence of neck injury in injured people wearing a helmet, even when adjusted for age (less than 6, between 6 and 12, or greater than 12 years old) and activity (skiing, snowboarding, snowblading).
A logistic regression model was constructed to compare the incidence of concussions to injury of some other body part. This model included the covariates sex $(M / F)$ and snow condition (soft/chunky/hard packed/ice/powder). An odds ratio of 1.610 for male participants (95\% CI 1.093 to 2.371 ) was obtained, meaning that the odds of concussion for male participants is more than 1.6 times the odds of concussion for female participants, when snow condition on the hill was taken into account. We found that the risk of concussion is also dependent on snow condition, when adjusted for sex. The odds of concussions for injuries sustained on chunky snow are almost 2.5 times that for injuries sustained on soft snow. Similarly, the odds of concussion on hard packed snow are more than 2.2 times that for soft snow. The odds ratios for ice and powder were not significant. There were no significant snow conditions/sex interactions; the effect of snow conditions on an individual's risk of concussion did not depend on the individual's sex.

\section{DISCUSSION \\ Snowbladers}

The characteristics of injured snowbladers have yet to be reported in the literature except for a case report of a "boot top" fracture. ${ }^{27}$ The percentage of snowbladers included in our sample is disproportionately high $(5.2 \%)$ compared with administrative and ski patroller estimates of the percentage of snowbladers on the hill (less than $0.5 \%$ ). This may be due to either an inherent risk involved in snowblading or a lower level of ability in the participants $(43.5 \%$ were beginners, $53.7 \%$ had never had a lesson). When injury patterns were analysed, the proportion of injuries to the shoulder (14.1\%) was slightly higher than in skiing $(9.1 \%)$ or snowboarding $(10.0 \%)$, but not significantly so $(\mathrm{p}=0.3590)$. The percentage of lower limb injuries $(56.4 \%)$ is higher than that for skiing and snowboarding $(42.2 \%$ and $13.8 \%$ respectively, $\mathrm{p}<0.0001)$. The percentage of leg injuries $(20.5 \%)$ is significantly higher than that for skiing and snowboarding $(6.9 \%$ and $0.8 \%$ respectively, $\mathrm{p}<0.0001)$. The most likely reason for the greater number of leg injuries in snowbladers is the non-releasable bindings on the snowblades. It is well known that the risk of lower extremity injury is higher when no binding release occurs or when binding adjustment is inadequate in skiers. ${ }^{711228}$ Johnson et al $^{13}$ found that the incidence of tibial fractures had declined by more than $88 \%$ between 1972 and 1994 with the introduction of release bindings and modern ski boots despite the fact that the incidence of grade III knee sprains had increased significantly over the same time period. Deibert et $a l^{7}$ also found a similar trend from 1972 to 1994, with an 89\% decrease in tibial fractures, which they attributed to advances in the release function of the ski boot binding system. They also noted a

\begin{tabular}{|c|c|c|c|c|}
\hline & Ski & Snowboard & Snowblade & p Value ${ }^{*}$ \\
\hline Total number of participants & 823 & 434 & 69 & \\
\hline Mean age (years) & $29.3(17.2)$ & $18.3(7.0)$ & $21.6(12.6)$ & $<0.0001$ \\
\hline $\begin{array}{l}\% \text { male } \\
\text { Self reported ability (\%) }\end{array}$ & 47.9 & 67.7 & 71.4 & $<0.0001$ \\
\hline Beginner & 22.2 & 28.6 & 43.5 & 0.0007 \\
\hline Novice & 12.4 & 9.1 & 8.7 & \\
\hline Intermediate & 35.2 & 36.3 & 27.5 & \\
\hline Advanced & 15.7 & 10.3 & 13 & \\
\hline Expert & 14.5 & 15.7 & 7.2 & \\
\hline Lessons (\% yes) & 79.1 & 61.2 & 46.3 & $<0.0001$ \\
\hline Equipment (\% owned) & 70 & 75.5 & 42 & $<0.0001$ \\
\hline Wearing helmet (\% yes) & 17.4 & 16.7 & 11.4 & 0.4612 \\
\hline
\end{tabular}




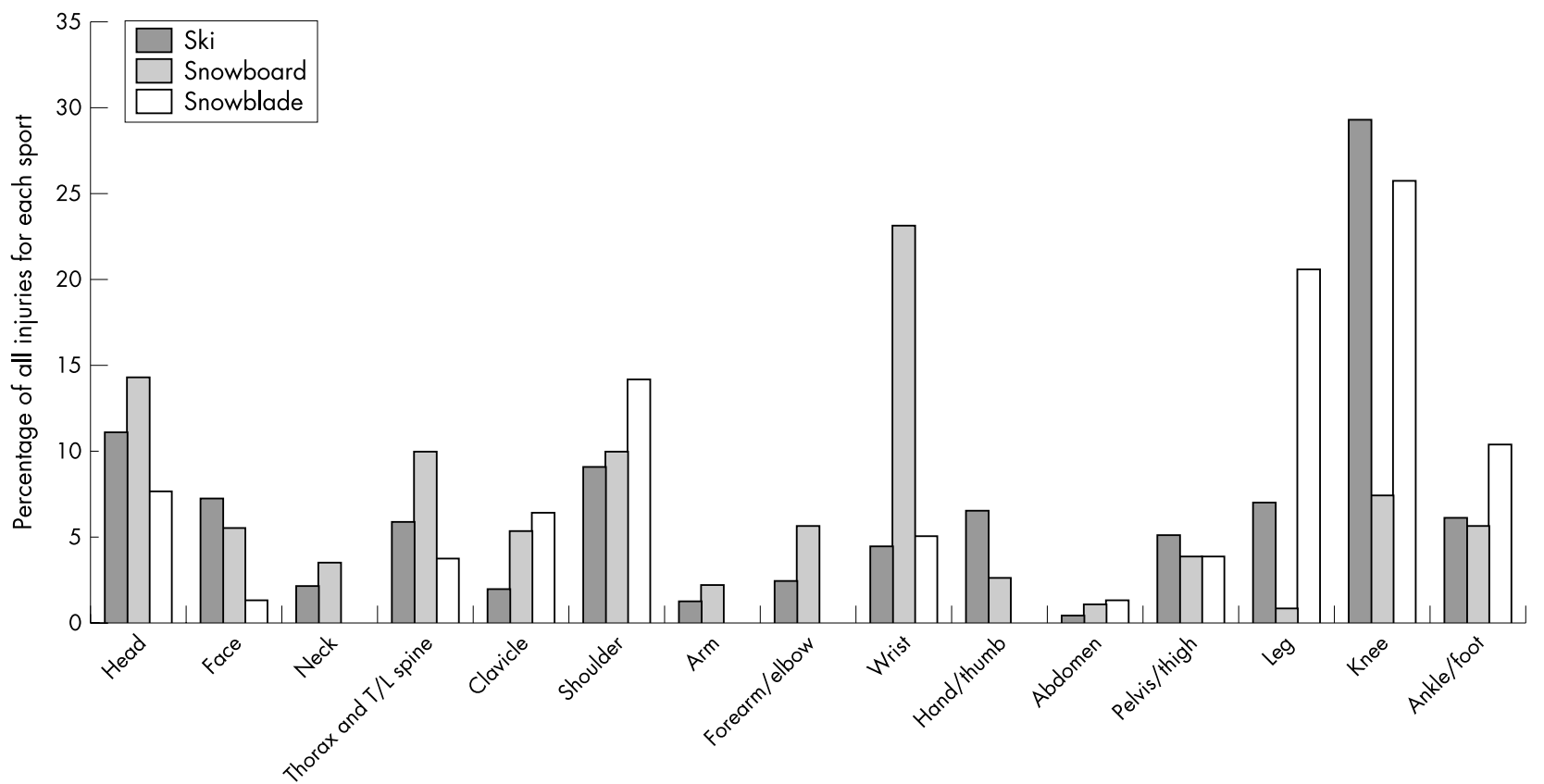

Site of injury

Figure 1 Injury percentages in each activity according to body site.

significant increase in anterior cruciate ligament injury. The manufacturers of snowblades should consider appropriate release bindings that are properly adjusted, such as those used in skiing, to replace the non-release type used at present. Advances in ski binding release technology and proper adjustment education should continue.

\section{Helmet use/concussion/neck injury}

There have been many advocates for the use of helmets in skiing and snowboarding. ${ }^{817} 2022$ 29-31 Nakaguchi et al ${ }^{16}$ advised measures be taken to protect the head, especially

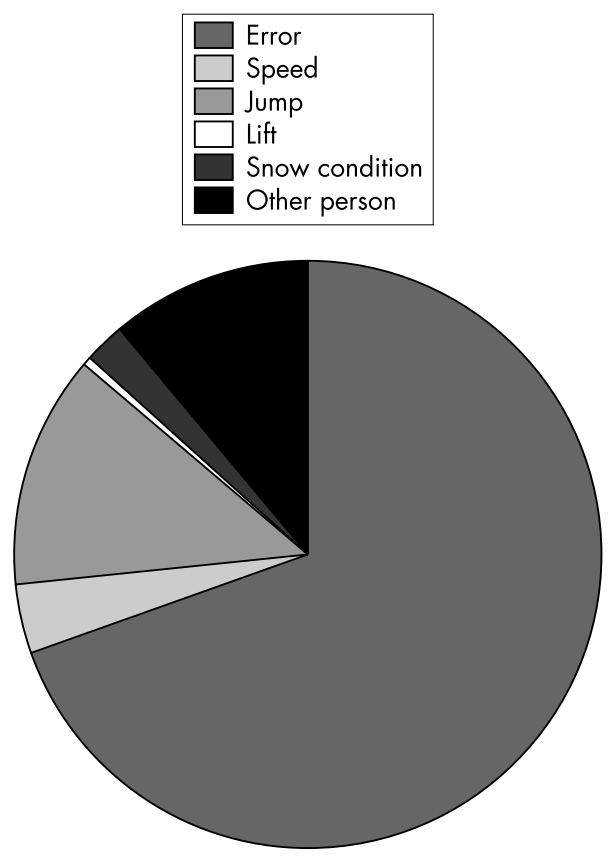

Figure 2 Percentage of each factor that was cited as causing the concussion for all activities combined. the occiput, in snowboarding. Sacco et $a l^{20}$ reported that helmets had not been worn by any of the skiers and snowboarders admitted to a level I trauma centre for head injuries or fatalities. Machold et al, ${ }^{14}$ in their questionnaire study, reported no head injuries in snowboarders wearing helmets, and $0.7 \%$ of all injuries were to the head in snowboarders not wearing a helmet. Hentschel et $a l^{31}$ found snowboarders suffered more significant head injuries than skiers and were more likely to require an intracranial procedure. They recommend the mandatory use of helmets.

However, there have been questions about the optimum design for helmets. ${ }^{15}$ Specifically, it has been suggested that there is a risk of associated neck or other injury in children wearing a helmet that is too large or heavy for them. ${ }^{7}$ Our study found no increase in neck or other injury associated with helmet use, even when adjusted for age and activity. This lack of harm combined with the value of helmets in reducing head injury in other sports, for example bicycling, ${ }^{32}$ ice hockey, ${ }^{33}$ and football, ${ }^{34}$ indicate that further study should be undertaken in alpine helmet design and efficacy to minimise effects of similar impact injuries.

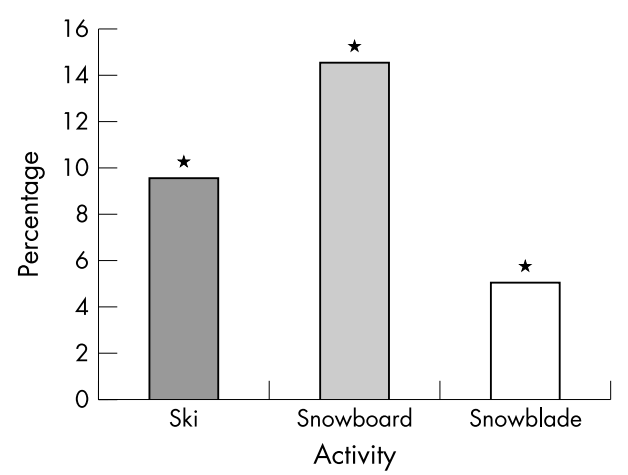

Figure 3 Concussion as a percentage of all injury in each activity. *Significantly different between groups. 
There was a significant association between neck injury and concussion. Those having neck injuries have significantly more concussions than those without neck injuries. Possible reasons for this include: whiplash type injury creating shearing forces in the cranial vault without an impact; an increase in the severity of injury, and therefore reporting, when both neck and head injury are present; people with neck injury are more likely to be asked about and therefore report symptoms of concussion.

It was interesting to note that male participants were at higher risk of head injury than female participants. This may in part be due to the type of activity in which they participate, for example jumping. Yamakawa et $a^{35}$ reported that over $70 \%$ of injuries to intermediate and expert snowboarders were a result of jumping, whereas Tarazi et al ${ }^{36}$ reported that $77 \%$ of all neck injuries to snowboarders was a s a result of jumps.

Overall, $18.5 \%(246 / 1332)$ of people had injuries to the head and face region. Other investigators using ski patrol, resort medical facility reports, or questionnaires found 4-37\% of injuries to the head and face. ${ }^{3579141517182137}$ Because the ski patrollers had been given an information session devoted to concussion before the start of the season, concussion may have been more readily identified than in previously reported studies. ${ }^{37}$ The necessity of uniform injury definitions in order to compare findings of different investigations has previously been stated. $^{38}$ When head injuries not requiring medical attention are not included in the definition of injury, the proportion of head injury is reported to be much lower. ${ }^{37}$ When a broader definition is used, the reported injury rates are similar. ${ }^{39}$ If data are taken from a hospital or trauma centre, the rates of head injury are higher (Shorter et al ${ }^{22}$ 44-71\%; Sacco et al ${ }^{20} 15 \%$; Prall et al ${ }^{19} 54 \%$ ). Sacco et al ${ }^{20}$ found blunt head trauma to be the most prevalent cause of death (54\%).

The obvious limitation in this type of investigation is that of underreporting and the lack of denominator data to determine if helmets decrease injury rate. Perhaps people wearing helmets are more likely to report head injury than those not. As well, concussion grade was not taken into account, and therefore the effect of helmet use on concussion severity was not evaluated. The only way to adequately assess the ability of a helmet to protect from head injury is to perform a randomised control trial with strict definitions of head injury, including concussion grade and adequate follow up. This type of study is difficult to undertake.

\section{Study limitations \\ Reporting}

The lack of denominator data for number of participants on the hill, number of participants in each activity, number of males versus females in each activity, and ages of all participants in each activity is a key problem in all studies of this nature. Because the exact number of skiers, snowboarders, snowbladers, and telemarkers present on the hill during the 1999-2000 season was an estimate only, injury rates were not calculated. Also, there were clinics and hospitals nearby, and it was assumed that a certain proportion of injured participants did not present to the ski patrol, but went directly to an alternative medical resource. One study dating back to the 1970s assessed injury rates by sending out questionnaires to ski school participants. ${ }^{40}$ They found the reporting rate of injured skiers to the ski patrol to be $40 \%$. Children under 12 were much more likely to report their injuries $(61 \%)$; there were no sex differences. The data presented here represent injured persons evaluated by the ski patrol only.
Take home message

Snowbladers are at greater risk of lower limb injuries than skiers and snowboarders. Wearing a helmet while skiing, snowboarding, or snowblading is not associated with any increased risk of other injury, including neck injury.

\section{Follow up}

An injury diagnosis was documented on the accident reports. However, most patrollers are not doctors and therefore a diagnosis on the report is not considered a physician diagnosis. No radiographs or other diagnostic procedures are carried out at the time of the injury report being filed. The definition for concussion had been clearly defined at the onset of data collection and was considered to be a diagnosis that could be made on site by the patrollers. Once the individual had left the patroller, there was no follow up information about the injury. Other investigators have used this reporting system and raised the same limitations to their study design. ${ }^{6}{ }^{10}$ Therefore, other than for concussion, neither injury type nor diagnosis was included in the results in this study.

\section{Future directions}

Collaborative efforts with the resort operators to obtain adequate data on the number, sex, age, activity, and protective gear worn by all participants will benefit epidemiological studies of this nature. For example, a specific pass type could be issued for the different activities, and age and sex could be entered into the resort database at the time of purchase. Controlled trials to assess the injury patterns associated with helmet and wrist guard use should be undertaken. Further research will endeavour to determine whether helmets could be optimally designed to protect against head injury. Snowblade manufacturers may consider redesign of binding systems to make them safer to protect against lower limb injuries. Education programmes directed at specific skills such as jumping should be in place to promote skill development and greater awareness of injuries that can occur as a result of risky behaviour.

\section{Summary}

Snowbladers have a unique pattern of injury, presenting with significantly more lower limb injuries than skiers or snowboarders. Equipment design should therefore be modified to decrease the number of such injuries. Also, safety education and skills techniques should be taught to those participating in high risk activities such as aerial manoeuvres. Head and face injuries represent $18.5 \%$ of all injuries reported to the ski patrol. Wearing a helmet was not associated with any increased incidence of other injury, including neck injury, even when adjusted for age.

\section{ACKNOWLEDGEMENTS}

Support for this project was provided by the Dr Tom Pashby Sports Safety Fund and from the American College of Surgeons (to KMJ). We would like to thank Sarah Fletcher, Andree Clement, Eric Gadoua, and the ski patrol at Mont Tremblant for their help with data collection. We would also like to thank Alison Organik for assistance with data input.

\section{Authors' affiliations}

E J Bridges, K M Johnston, McGill Sports Medicine Center, Montreal, Quebec, Canada

F Rouah, Department of Mathematics and Statistics, McGill University, Montreal 
K M Johnston, Departments of Neurosurgery and Neurotrauma, McGill University

\section{REFERENCES}

1 Abu-Laban RB. Snowboarding injuries: an analysis and comparison with alpine skiing injuries. CMAJ 1991;145:1097-103.

2 Bladin C, Giddings P, Robinson M. Australian snowboard injury database study: a four-year prospective study. Am J Sports Med 1993;21:701-4.

3 Calle SC, Evans JT. Snowboarding trauma. J Pediatr Surg 1995;30:791-4.

4 Chow TK, Corbett SW, Farstad DJ. Spectrum of injuries from snowboarding. J Trauma 1996;41:321-5.

5 Davidson TM, Laliotis AT. Snowboarding injuries, a four year study with comparison with alpine ski injuries. Western J Med 1996;164:231-7.

6 Davidson TM, Laliotis AT. Alpine skiing injuries. A nine year study. West J Med 1996;164:310-14.

7 Deibert MC, Aronsson DD, Johnson RJ, et al. Skiing injuries in children, adolescents, and adults. J Bone Joint Surg [Am] 1998;80:25-32.

8 Ekeland A, Nordsletten L, Lystad H, et al. Alpine skiing injuries in children. In: Johnson RJ, Mote CD, Zelcer J, eds. Skiing trauma and safety: Proceedings of the Ninth International Symposium (ASTM STP 1182). Philadelphia, PA: American Society For Testing and Materials, 1993:43-9.

9 Ganong RB, Heneveld EH, Beranek SR, et al. Snowboarding injuries; a report of 415 patients. Physician and Sports Medicine 1992;20:114-22.

10 Hagel BE, Meeuwisse WH, Mohtadi NGH, et al. Skiing and snowboarding injuries in children and adolescents of southern Alberta. Clin J Sport Med 1999;9:9-17.

11 Hauser W. Experimental prospective skiing injury study. In: Johnson RJ, Mote $C D$, Binet $M-H$, eds. Skiing trauma and safety: Proceedings of the Seventh International Symposium (ASTM STP 1022). Philadelphia, PA: American Society For Testing and Materials, 1989:18-24.

12 Johnson RJ, Ettlinger CF, Shealy JE. Skier injury trends. In: Johnson RJ, Mote $\mathrm{CD}$, Binet $\mathrm{M}-\mathrm{H}$, eds. Skiing trauma and safety: Proceedings of the Seventh International Symposium (ASTM STP 1022). Philadelphia, PA: American Society For Testing and Materials, 1989:25-31.

13 Johnson RJ, Ettlinger CF, Shealy JE. Ski injury trends 1972-1994. In: Johnson RJ, Mote CD Jr, Ekeland A, eds. Ski trauma and safety. Philadelphia, PA: American Society For Testing and Materials, 1997; 11:37-48

14 Machold W, Kwasny O, GaBler P, et al. Risk of injury through snowboarding J Trauma 2000;48:1109-14.

15 MacNab AJ, Cadman R. Demographics of alpine skiing and snowboarding injury: lessons for prevention programs. Injury Prevention 1996;2:286-9.

16 Nakaguchi H, Fujimaki T, Ueki K, et al. Snowboard head injury: prospective study in Chino, Nagano, for two seasons from 1995 to 1997. J Trauma 1999;46:1066-9

17 O'Neill DF, McGlone MR. Injury risk in first-time snowboarders versus firsttime skiers. Am J Sports Med 1999;27:94-7.

18 Pino EC, Colville MR. Snowboard injuries. Am J Sports Med 1989; 17:778-81.
19 Prall JA, Winston KR, Brennan R. Severe snowboarding injuries. Injury 1995;26:539-42

20 Sacco DE, Sartorelli DH, Vane DW. Evaluation of alpine skiing and snowboarding injury in a northeastern state. J Trauma 1998:44:654-9.

21 Shealy JE. Snowboarding vs. downhill skiing injuries. In: Johnson RJ, Mote CD, Zelcer J, eds. Skiing trauma and safety: Proceedings of the Ninth International Symposium (ASTM STP 1 182). Philadelphia, PA: American Society for Testing and Evaluation, 1993:241-54.

22 Shorter NA, Jensen PE, Harmon BJ, et al. Skiing injuries in children and adolescents. J Trauma 1996;40:997-1001.

23 Shorter NA, Mooney DP, Harmon BJ. Snowboarding injuries in children and adolescents. Am J Emerg Med 1999;17:261-3.

24 Sutherland AG, Holmes JD, Myers S. Differing injury patterns in snowboarding and alpine skiing. Injury 1996;27:423-5.

25 SAS. SAS/STAT user's guide. Version 6, Volumes I and II Cary, NC: SAS Institute Inc, 1990.

26 Hosmer DW Jr, Lemeshow S. Applied logistic regression. New York: John Wiley \& Sons, 1989.

27 Holowenko D, Philipp R, MacDonald PB. Fractured tibia and fibula during use of "snowblades": implications of the return of nonrelease bindings. Clin J Sport Med 2000; 10:67-8.

28 Bouter LM, Knipschild PG, Volovics A. Binding function in relation to injury risk in downhill skiing. Am J Sports Med 1989;17:226-33.

29 Chissell HR, Feagin JA, Warme WJ, et al. Trends in ski and snowboard injuries. Sports Med 1996;22:141-5.

30 US Consumer Product Safety Commission. Skiing helmets; an evaluation of the potential to reduce head injury. Jan 1999. Available from www.cpsc.gov/ library/skihelm.pdf.

31 Hentschel S, Hader W, Boyd M. Head injuries in skiers and snowboarders in British Columbia. Can J Neurol Sci 2001;28:42-6.

32 Weiss BD. Bicycle-related head injuries. Clin Sports Med 1994;13:99-112.

33 Tator CH. Neck injuries in ice hockey: a recent, unresolved problem with many contributing factors. Clin Sports Med 1987;6:101-14.

34 Cantu RC. Head injuries in sport. Br J Sports Med 1996;30:289-96.

35 Yamakawa H, Murase S, Sakai H, et al. Spinal injuries in snowboarders: risk of jumping as an integral part of snowboarding. J Trauma 2001;50:1101-5.

36 Tarazi F, Dvorak MF, Wing PC. Spinal injuries in skiers and snowboarders. Am J Sports Med 1999;27:177-80.

37 Blitzer CM, Johnson RJ, Etllinger CF, et al. Downhill skiing injuries in children. Am J Sports Med 1984;12:142-7.

38 Meeuwisse W, Love E. Athletic injury reporting: development of universal systems. Clin J Sport Med 1997;24:184-203.

39 Cadman R, Macnab AJ. Age and gender: two epidemiological factors in skiing and snowboarding injury. In: Mote CD Jr, Johnson RJ, Hauser W, et al, eds. Skiing trauma and safety (ASTM STP 1266). Philadelphia: American Society for Testing and Materials, 1996;10:58-65.

40 Requa RK, Toney JM, Garrick JG. Parameters of injury reporting in skiing. Med Sci Sports 1977;9:185-90. 